not yet been decided. The only hint of a change in the work of the survey is the intention of expanding the biological side, on advice from the Council for Scientific Policy. The budget of the survey, however, is unlikely to be increased, unless the magic word "oceanography" is muttered sufficiently often. The council has two oceanographic enthusiasms; one is to study the North Atlantic, for some people are afraid that it is getting significantly colder, which could have catastrophic effects on the stock of fish; the other is to investigate ways of extracting uranium, gold, and silver from sea water by ion exchange. The process is not commercial yet, but might be if uranium prices increased, or if the French view on the price of gold prevailed. The Nature Conservancy, bloody but unbowed after its unavailing struggle with Imperial Chemical Industries, Ltd., over the building of a reservoir in Teesdale, has not yet decided whether to take ICI up on its offer of $£ 100,000$ for a crash course of research into the botany of Teesdale. It should make up its mind quickly, before ICI forgets it ever made the offer.

\section{Technology Gap}

LAST week (March 6) a one-day meeting at the Institution of Electrical Engineers under the title "Making the Bosworth Report Work" discussed the means of attracting more able graduates into industry. It has been a constant theme of the Ministry of Technology, which sponsored the conference, that industry and the universities should draw closer together, but it is not yet clear whether its pious pleas are having any effect.

In some respects university departments are showing themselves more responsive than industrial firmsapart, of course, from those traditionally employing graduates. At the beginning of the year, four of the physics staff at University College, London, opened a consultative practice (as a limited company, New Industrial Concepts, Ltd.) to advise firms with process control and inspection problems. Their experience with manufacturers has shown that small British companies in particular seldom know how even wellestablished electronic techniques can help them; really advanced methods are a closed book. "There are still an astonishing number of standard jobs done by hand and measurements made by eye ...."

The group-Dr. R. Stebbings, Dr. D. G. Davis, Dr. A. Boksenberg and Dr. A. C. H. Smith-have already nearly completed their first commission-to solve a control problem (including fabricating a unit) in the manufacture of specialized electric light bulbs -and have a satisfied client. They have undertaken that their commercial excursion shall not interfere with their lecturing and research commitments at University College, but apart from this the college has made no conditions and has been encouraging. So has the Ministry of Technology, which has put the group in touch with its regional liaison officers. The group have not asked for a grant so they have not got one.

Rather different is the scheme headed by Dr. Kenneth Ball at the Department of Mechanical Engineering at the University of Liverpool, now in its fourth year and supported by a grant of $£ 32,000$ from the Science Research Council. In this case the academic team has sought opportunities to get into the shop and design specific pieces of plant for actual use. "Industrial jobs provide us with a laboratory where we can create a design, and then look backwards at it," says Dr. Ball. "Not until a real job is tackled can one identify either the central problems of systems design or of teaching systems designing . . ." The most substantial job tackled so far has been in association with Ruston and Hornsby, Ltd. (matching a freshly designed turbo-charger to its diesel engine), and evolving computer software to project further engine development.

\section{Best Buy in Space}

An agreement signed on March 8 between the European Space Research Organization (ESRO) and the U.S. National Aeronautics and Space Administration may mean that British taxpayers will have to contribute more towards ESRO launchings than towards other means of putting their experiments into satellites. The new agreement lays down that ESRO will in future pay for satellite experiments launched by the United States. In practice, however, well-established research groups in Britain have hitherto been able to include their experimental equipment in American satellites without payment of any kind except that which is invested in hardware. Groups from University College, London, the Culham Laboratory of the Atomic Energy Authority, and the R.A.F. Institute of Aviation Medicine are among those who have been able to find space in American satellites.

From an exclusively British point of view, ESRO launchings are expensive, and now increasingly so, because the British contribution towards the running costs of the organization, including the cost of launching rockets, is roughly 25 per cent of the total budget. This contribution is payable whether or not British experiments are included in ESRO satellites although the costs of salaries and equipment for particular experiments come out of separate national budgets. The first ESRO launch under the agreement with the United States will be the satellite due to be launched into a highly elliptical orbit in late 1968 to record events in the magnetosphere at around the next solar maximum. The contract with NASA is for just under $\$ 4$ million and the cost of the satellite and its equipment will be roughly the same again. Later American launchings of ESRO satellites will be relatively cheaper because of the comparative sophistication of their payloads costing roughly $£ 8$ million for the two.

In the circumstances, the British national space programme, much maligned, may yet be the second best buy, at least on the surface. The Black Arrow satellite payloads now in the offing should be comparatively cheap to launch if only because a large part of the cost will be hidden in the defence budget.

\section{Another Exhortation}

The United States National Committee for the International Biological Programme has now published a more detailed outline of the kind of research it is anxious to encourage when the second phase of the operation begins in July this year. The document U.S. Participation in the International Biological Programme is the second of two reports to have been produced by the committee, and is to be had from the 